\title{
A DESCRIPTIVE STUDY TO ASSESS THE KNOWLEDGE REGARDING HEALTH BENEFITS OF YOGA AMONG THE ADOLESCENTS STUDYING IN SELECTED SR. SEC. SCHOOLS AT JODHPUR, WITH A VIEW TO DEVELOP AN INFORMATION BOOKLET
}

\author{
Manish Kumar \\ M.Sc. Nursing, Community Health Nursing, Mai Khadija Institute of Nursing Sciences, Jodhpur, \\ Rajasthan
}

Article DOI: https://doi.org/10.36713/epra8714 DOI No: $10.36713 /$ epra8714

\begin{abstract}
INTRODUCTION: The word Yoga is derived from the Sanskrit word "to join" or "unity." It is described in spiritual terms as union of the individual consciousness with the universal consciousness. In another term, Yoga is the "union of mind and body" for balancing and harmonizing the physical and mental functions of body. This is done through the practice of physical postures (asana), breathing control (pranayama), and meditation. In this study, distribution of booklet among adolescents is an attempt to improve the knowledge regarding health benefits of yoga.

AIM OF THE STUDY: Assess the knowledge regarding health benefits of yoga among adolescents.

METERIAL AND METHOD: A descriptive study was carried out to assess the knowledge of 60 adolescents selected by purposive sampling, who were studying in selected sr. sec. school at jodhpur Rajasthan were assessed by using a structured knowledge questionnaire and analyzed by using descriptive and inferential statistics were used for data analysis.

RESULT: Therefor percentage distribution the sample with reference shows that majority of adolescents have $(83.33 \%)$ poor and (16.66\%) average and no one has good knowledge of health benefits of yoga. However the majority of the demographic variables like gender, religion, area of residents, education of father, types of family, previous attend any yoga programme were not significant at 0.05 level.

CONCLUSION: It can be concluded the adolescent's students are having poor knowledge regarding health benefits of yoga. There are very important to Provides institutional and academic knowledge for yoga theory and practice. So I request to respected department of education to added the yoga subject in primary to Sr. sec academic season for improve student's health physically, mentally and spiritually health lifestyle. Self-information booklets were distributed to them to improve the knowledge regarding health benefits of yoga.

KEY WORDS: Knowledge, adolescents, Health benefits of yoga, Information booklet.
\end{abstract}

\section{INTRODUCTION \& BACKGROUND OF THE STUDY}

Yoga originated from India thousands of years ago. It has been described in Bhagavad - Gita and Pat Anjali - Darshan, Bhagavad - Gita defines it as lifestyle with consuming appropriate food, doing appropriate exercise, discharging duties properly, going early to bed, and getting up early. All these comprise Yoga and are shot way of remaining healthy without suffering. This definition is comparable to an aphorism quoted by Peter McDonald - there best physicians are the doctors quite, and doctors "e merry man.

Before discussing the importance of Yoga in modern lifestyles. It is essential to discuss the problems associated with modern life. It is obvious that modern lifestyles are easing the life of today's 
man. However, it also has a negative effect on health both physically, socially, psychologically and spiritually. The reasons for such problems are multiple to mention some of them are lack of physical exercises, using technology given machine for easing life and spending much of our time on these machines, moving with transportation from place to place and sitting long hours in the office and in front of computers are some of them. Modern lifestyle intensifies the risk of fatness or obesity.

Yoga has an important role in Modern medicine. Many researches are going on about yoga for good health. One of the main etiologic factors for any disease is stress, yoga has a greater impact on reduction of stress and stress related disorders. Various studies indicate that chronic emotional stress disturbs the blood pressure mechanism and cholesterol level. Various scientific studies have revealed that appropriate changes in the life style on the basis of yogic principles can even reverse the heart disease and would help us in maintain our healthy state of body and mind and to prevent such stress disorders.

According to WHO - "Health is a state of complete physical, mental and social well-being and not merely an absence of disease or infirmity" (WHO 1964). Hence the contribution of yoga in providing this integrated whole benefit to individuals who practicing yoga in the day to day life is huge. Regular yoga practice builds mental lucidity and coolness, boost body awareness, relieves stress patterns, relaxes the minds and sharpens concentration. Yoga provides tools through which one can manage which the pain and helps contradict with the feeling of helplessness and depression (Verma 2015).

"While addressing the 69th session of United Nations General Assembly (UNGA) on September 27, 2014, the Honorable Prime Minister of India Shri Narendra Modi urged the world community to adopt an International Day of Yoga. "Yoga is an invaluable gift of ancient Indian tradition. It embodies unity of mind and body; thought and action; restraint and fulfilment."

Yoga is being practiced worldwide today. Approximately 2 billion people around the world practice Yoga. According to a survey, it is said that number of Americans doing yoga has grown by $50 \%$ over the last few years to over 36 million as of 2016 from 20.4 million in 2012. In addition to these 9 out of 10 Americans have heard of Yoga, one in three have tried yoga at least once and more than $15 \%$ of Americans have done Yoga in the past six months. Yoga is an ancient physical, mental and spiritual practice that originated in India and is now practiced in various forms around the world. Indians have known the importance of Yoga from decades and from last many years the whole world is talking, practicing and adopting Yoga and its benefits.

To achieve target knowledge regarding health benefits of yoga among the adolescents are the most important factor. So, the researcher was motivated to conduct this study to find the level of knowledge regarding health benefits of yoga and educate them through information booklet.

\section{OBJECTIVES OF THE STUDY}

- To assess the knowledge regarding health benefits of yoga among the adolescents studying in selected Sr. Sec. Schools at Jodhpur.

- To find out an association between the level of knowledge regarding health benefits of yoga among the adolescents with selected demographical variables.

- To develop an information booklet regarding health benefits of yoga.

\section{HYPOTHESIS OF THE STUDY}

- H1There is a significant association between the level of knowledge regarding health benefits of yoga among the adolescents and selected demographic variables at the level of $\mathrm{P}<0.05$.

\section{OPERATIONAL DEFINITION}

- Assess- Assess refers to an activity to estimate the knowledge of health benefits of yoga among the adolescents.

- Knowledge: Refers to the correct responses obtained from adolescents regarding health benefits of yoga through a structured knowledge questionnaire.

- Adolescents: Refers to boys and girls studying at selected school level between the group of 16-18 years.

- Health benefits: Refers to includes deep breathing, relaxation and focused attention which can improve physical posture, sleep and have added metal health or spiritual benefits.

- Yoga: Yoga is recognized as a form of mindbody exercises improve muscle strength, flexibility, blood circulation and oxygen uptake as well as hormone function. In addition, the relaxation induced by meditation helps to stabilize the autonomic nervous system with a tendency towards parasympathetic dominance.

- Information booklet: In this study, it refers to the educational tool prepared by the investigator to generate knowledge regarding health benefits yoga. 


\section{ASSUMPTION}

- Adolescents may have some knowledge regarding health benefits of yoga.

- Adolescent's knowledge regarding health benefits of yoga can be improved by the Information booklet.

\section{DELIMITATION}

The study is delimited to the adolescents studying in selected Sr. Sec. School at Jodhpur.

\section{RESEARCH METHODOLOGY \\ - RESEARCH APPROACH}

Quantitative research approach is considered appropriate for the present study.

- RESEARCH DESIGN

Descriptive survey design was adopted for this study. RESEARCH VARIABLE

- Research variable

Research variables are those variable which are observed a measured in natural setting as they exist without any manipulation in the descriptive study no last effect relationship is examined. In my study the research variables is knowledge, regarding health benefits of yoga.

- Demographic variable

Demographic variables are the characteristics and attributes of the study sample. In my study the demographic variables are gender, religion, and area of residence, parent's education status, type of family and previously attended any yoga programme.

\section{POPULATION}

Adolescents studying in selected Sr. Sec. School at Jodhpur.

\section{SAMPLING SIZE}

In this study, the sample consists 60 Adolescents studying in XI and XII class from Diamond ser. Sec. School at Jodhpur, Diamond Academy.

\section{SAMPLING TECHNIQUE}

Non-probability purposive sampling

technique was used for this study.

\section{RELIABLITY OF THE TOOL}

The reliability was established by using Cronbach's Alpha Coefficient formula and it is found to be reliable $(\mathrm{r}=0.726)$.

\section{MAJOR FINDING OF THE STUDY}

Table 1 Depicted that of adolescents participated in the study, Gender - Female (32, $53.33 \%)$, Religion -Hindu (59, $98.33 \%)$, Area of Residence -Urban (39, 65\%), Education of Father High secondary school $(19,31.67 \%)$, Education status of Mother - Illiterate $(27,45 \%)$, Types of Family - nuclear family (34, 56.67\%), Previous attend programme - No $(33,55 \%)$.

Table 2 Depicted that our interpretation level of knowledge regarding health benefits of yoga among adolescents out of 60 samples, majority 50 $(83.33 \%)$ have Poor $(<50 \%)$ Knowledge, 10 $(16.66 \%)$ have average (50-75 \%) knowledge, 0 $(00 \%)$ have good $(>75 \%)$ knowledge regarding health benefits of yoga.

Table 3 Depicted shows that the adolescents have knowledge regarding introduction of yoga contain max. Score 5, mean have 2.62, SD have \pm 1.21 and mean $\%$ have $52.4 \%$, knowledge aspect in general knowledge of yoga contain Max score 5 mean have 1.97SD have \pm 0.95 and Mean\% have $39.4 \%$, knowledge aspect in health benefits of yoga. Found the Max score 20, mean have 6.5, SD have \pm 2.75 and mean\% have $32.75 \%$ While assess the knowledge regarding health benefits of yoga among the adolescents, I found that the total max score 30, mean have11.9, SD is \pm 4.91 . and total mean\% have $124.55 \%$.

Based on the findings we can conclude that the knowledge of adolescent regarding health benefits of yoga have been poor regarding all different aspects of the health benefits of yoga. 


\section{EPRA International Journal of Research and Development (IJRD)}

Volume: 6 | Issue: 10 | October 2021

- Peer Reviewed Journal

Table 1. Frequency and percentage distribution of demographic variables among adolescents $(\mathrm{N}=60)$

\begin{tabular}{|c|c|c|c|c|}
\hline S. No & \multicolumn{2}{|c|}{ Socio-demographic variable } & Frequency & Percentage \\
\hline 1 & Gender & $\begin{array}{l}\text { Male } \\
\text { Female }\end{array}$ & $\begin{array}{l}28 \\
32\end{array}$ & $\begin{array}{l}46.67 \% \\
53.33 \%\end{array}$ \\
\hline 2 & Religion & $\begin{array}{c}\text { Hindu } \\
\text { Christian }\end{array}$ & $\begin{array}{l}59 \\
01\end{array}$ & $\begin{array}{c}98.33 \% \\
1.67 \%\end{array}$ \\
\hline 3 & Area of Residence & $\begin{array}{l}\text { Urban } \\
\text { Rural }\end{array}$ & $\begin{array}{l}39 \\
21\end{array}$ & $\begin{array}{l}65 \\
35\end{array}$ \\
\hline 4 & Education of Father & $\begin{array}{c}\text { Illiterate } \\
\text { Primary school } \\
\text { Secondary school } \\
\text { High secondary school } \\
\text { Degree and above }\end{array}$ & $\begin{array}{c}3 \\
10 \\
16 \\
19 \\
12\end{array}$ & $\begin{array}{c}5 \\
16.67 \\
26.67 \\
31.67 \\
20\end{array}$ \\
\hline 5 & Education status of Mother & $\begin{array}{c}\text { Illiterate } \\
\text { Primary school } \\
\text { Secondary school } \\
\text { High secondary school } \\
\text { Degree and above }\end{array}$ & $\begin{array}{c}27 \\
19 \\
8 \\
5 \\
1\end{array}$ & $\begin{array}{c}45 \\
31.67 \\
13.33 \\
8.33 \\
1.67\end{array}$ \\
\hline 6 & Types Of Family & $\begin{array}{l}\text { Nuclear family } \\
\text { Joint family }\end{array}$ & $\begin{array}{l}34 \\
26\end{array}$ & $\begin{array}{l}56.67 \\
43.33\end{array}$ \\
\hline 7 & Previous attend programme & $\begin{array}{l}\text { Yes } \\
\text { No }\end{array}$ & $\begin{array}{l}27 \\
33\end{array}$ & $\begin{array}{l}45 \\
55\end{array}$ \\
\hline
\end{tabular}

Table 2. Level of knowledge regarding health benefits of yoga

\begin{tabular}{|c|c|c|}
\hline Level of Awareness & Frequency & Percentage \\
\hline Poor $(<50 \%)$ & 50 & $83.33 \%$ \\
\hline Average $(50-70 \%)$ & 10 & $16.66 \%$ \\
\hline Good $(>75 \%)$ & 00 & $00 \%$ \\
\hline Total & $\mathbf{1 0 0}$ & $\mathbf{1 0 0 . 0 \%}$ \\
\hline
\end{tabular}

Table 3. Aspect wise mean, SD and mean percentage knowledge scores ofrespondents on health benefits of yoga among the adolescents $(\mathrm{N}=60)$

\begin{tabular}{|c|c|c|c|c|c|}
\hline & \multirow{2}{*}{ Knowledge Aspects } & \multirow{2}{*}{$\begin{array}{c}\text { Max. Possible } \\
\text { No. }\end{array}$} & & \multicolumn{3}{|c|}{ Respondents Knowledge } \\
\cline { 3 - 6 } & & 5 & Mean & Mean (\%) & SD \\
\hline 1 & Introduction of yoga & 2.62 & 52.4 & 1.21 \\
\hline 2 & General knowledge of yoga & 5 & 1.97 & 39.4 & 0.95 \\
\hline 3 & Health benefits of yoga & 20 & 6.5 & 32.75 & 2.75 \\
\hline & Total & $\mathbf{3 0}$ & $\mathbf{1 1 . 9}$ & $\mathbf{1 2 4 . 5 5}$ & $\mathbf{4 . 9 1}$ \\
\hline
\end{tabular}

\section{DISCUSSION}

The findings of this study that our interpretation level of knowledge regarding health benefits of yoga among adolescents out of 60 samples, majority $50(83.33 \%)$ have Poor $(<50 \%)$ Knowledge, $10(16.66 \%)$ have average (50-75\%) knowledge, $0(00 \%)$ have good (> $75 \%)$ knowledge.

\section{CONCLUSION}

The following conclusions were drawn on the basis of the present study to assess the knowledge regarding health benefits of yoga among the adolescents studying in selected sr. sec. school at Jodhpur. Therefor percentage distribution the sample with reference shows that majority of adolescents have $(83.33 \%)$ poor and $(16.66 \%)$ average and no one has good knowledge of health benefits of yoga. The knowledge level regarding health benefits of yoga among the adolescents studying in selected sr. sec. school and selected demographic variable. Variables like gender, religion, area of residents, education of father, types of family, previous attend any yoga programme were not significant at 0.05 level.

The study shows that the adolescent's students are having poor knowledge regarding health benefits of yoga. There are very important to Provides institutional and academic knowledge for yoga theory and practice. So I request to respected department of 
education to added the yoga subject in primary to $\mathrm{Sr}$. sec academic season for improve student's health physically, mentally and spiritually health lifestyle.

\section{REFERENCES}

1. Armour M, Sinclair J, Chalmers $K J$, Smith $C A$ , (2019) self - management strategies amongst Australian women with endometriosis: a national online survey. Armour et al. BMC complementary and alternative medicine 19:17 https: //doi.org/10.1186/s12906-019-2431-x.

2. Bolton RE, Fix GM, Lukas V, Bokhour BG, 2018 Bio psychosocial benefits of movement-based complementary and integrative health therapies for patients with chronic condition. Chronic lllm. jan 1:1742395318782377. Doi: 10.1177/ 1742395318782377. Available from https://www.ncbi.nlm.nih.gov/pubmed/29911426 4.

3. Bussing A, Michalsen A, Khalsha SBS, Telles A, Sherman KJ. 2012 Effects of yoga onmental and physical health a short summary of reviews. Hindawi publication corporation evidence- based complementary and alternation medicine . july 18: vol. 2012 p7. doi:10.1155/2012/165410.

4. Cramer H, Thoms MS, Anheyer D, Lauche R, Dbos G. 2016;Yoga in women with abdominal obesity-a randomize controlled trial.Disch Artebl Int 113;645-52.doi: 10.3238/arztebl.2016.0645.

5. Conboy LA, Noggle JJ, Frey JI, Kudesia RS, Khalsha SBS. 2013 Qualitative evaluation of a high school yoga program. Feasibility and perceived benefits. Elsevier Inc. Explore 2013 mayl june vol.9,no.3. http://dx.doi.org/10.1016/j.explore.2013.02.001

6. Cushing $R E$, DrPH, Braun $K L$, Alden S, Iayt $C$, Ryt E, 2018 A Qualitative Study Exploring Yoga in Veterans with Post Traumatic Stress Disease Symptoms Int J yoga therapy (28). Available from www.IAYT.org

7. Divya TS, vijayalakshmi MT, Mini K, Pushpalatha M, Suresh V, 2019 cardiopulmonary and metabolic effects of yoga in healthy volunteers 115-120

8. wais T, Begun J, Kenny M, Rickett K, Hay K, Ajilchi B, Kisely S. 2019 A systematic review and meta- analysis of mindfulness based intervention and yoga in inflammatory bowel disease Journal of Psychosomatic Research 116()44-53

9. Groessl E J, Maiya M, Scehmalzl L, Wing D, Jeste DV . 2018 Yoga prevent mobility limitation in older adults:feasibility of a rendomized controlled trial grossl etal BMC. 